\title{
On the neutrosophic soft set with rough set theory
}

\author{
Minakhi Das ${ }^{1}$ (D) $\cdot$ Debadutta Mohanty $^{2} \cdot$ Kedar Chandra Parida $^{3}$ \\ Accepted: 27 July 2021 / Published online: 24 August 2021 \\ (c) The Author(s), under exclusive licence to Springer-Verlag GmbH Germany, part of Springer Nature 2021
}

\begin{abstract}
Rough set is a very powerful invention to the whole world for dealing with uncertain, incomplete and imprecise problems. Also soft set theory and neutrosophic set theory are advance mathematical tools to handle these uncertain, incomplete, inconsistent information in a better way. The purpose of this article is to expand the scope of rough set, soft set and neutrosophic set theory. We have introduced the concept of neutrosophic soft set with roughness without using full soft set. Some definitions, properties and examples have been established on neutrosophic soft rough set. Moreover, dispensable and equalities are written on roughness with neutrosophic soft set.
\end{abstract}

Keywords Rough set $\cdot$ Soft set $\cdot$ Neutrosophic set $\cdot$ Neutrosophic soft approximation operators $\cdot$ Neutrosophic soft rough set

\section{Introduction}

The rough set theory was introduced by Pawlak (1982). The advanced mathematical theory has enlightened the researchers of Artificial Intelligence, Mathematics and Computer Science. An inexact set $S$ is categorized by two exact sets that is the lower approximation and upper approximation of the set $\mathrm{S}$ through an equivalence relation. Rough set is based on the knowledge about one's ability to discern the objects, data, phenomenon etc. In 1983, zakowski defined the rough set using the covering instead of equivalence relation (or partition) where the lower approximation of the set $S$ is the interior of $S$ and upper approximation of $S$ is the closure of $S$. Later Lin (1988) defined rough set through neighborhood operators(a new covering). Many researchers have found different approximation operators based on the covering and 1-neighborhood operators.

Minakhi Das

minakhidas55@gmail.com

Debadutta Mohanty

debadutta.mohanty@rediffmail.com

Kedar Chandra Parida

kedarparida@yahoo.com

1 Department of Mathematics, North Orissa University, Mayurbhanj, Odisha, India

2 Department of Mathematics, Seemanta Mahavidyalaya, Mayurbhanj, Odisha, India

3 Department of Mathematics, B.B College, Mayurbhanj, Odisha, India
Smarandache (1999) introduced the concept of neutrospohic set. Neutrosophic set is described by three functions: a membership function, indeterminacy function and a non-membership function. The functions are independently related, where the membership, indeterminacy and non-membership functional values belong to $]^{-} 0,1^{+}[$.

And then, in the same year, D. Molodtsov proposed the soft set theory for dealing with uncertainties. The soft set is defined through a parameter set $A$ and a mapping $F$ is defined from $A$ to power set of the universal set. Soft set theory has a potential for application in several directions. Maji et al. (2003) narrate the operations AND, OR, Compliment and other set theoretic operations which attract the researchers to study more on soft set theory. Feng et al. (2010) published a paper on soft rough set and rough soft set. In Shabir et al. (2013) introduced Modified Soft Rough sets. P.K. Maji in 2013 brought forth the concept neutrosophic soft set. Bhutani and Aggarwal (2017) defined neutrosophic rough soft sets and A. Al-Quran, N. Hassan and E. Marei defined neutrosophic soft rough set in 2019. In the year 2020 (Zhang et al. 2020) studied neutrosophic fusion of rough set theory. Also an extension was made from soft set to Hypersoft set transforming the function into a multi-attribute function in the year 2018 by F. Smarandache. Das and Mohanty (2021) defined soft rough set not using full soft set and studied dispensability and other properties of soft rough set.

In this paper, we have defined roughness on neutrosophic soft set in a new manner which is different from the definitions given by Al-Quran et al. (2019). In the paper, A. 
Al-Quran et al. had considered the full soft set to define neutrosophic soft rough set. The definition given here will be more effective approach to handle the uncertain, vague and imprecise data as the full soft is not used.

\section{Preliminaries}

\subsection{Rough set}

The definition and some properties of rough set introduced by Z. Pawlak are presented here. Let $U$ be the universal set and $M$ be an equivalence relation(a knowledge) on $U$, where $M$ is termed as indiscernibility relation. $U / M$ be the family of all equivalence classes of $M$ known as categories or concepts of $M$ and for $x \in U,[x]_{M}$ is an equivalence class of $x$. The relational system $K=(U, M)$ is called a approximation space. The $M$-lower and $M$-upper approximations of a set $X \subseteq U$ under the indiscernibilty relation $M$ are defined as

$\underline{M} X=\left\{x \in U:[x]_{M} \subseteq X\right\}$ and

$\bar{M} X=\left\{x \in U:[x]_{M} \cap X \neq \phi\right\}$, respectively.

Definition 2.1 (Pawlak 1982) Let $U$ be universal set and $M$ be an equivalence relation(a knowledge) on $U$. For the set $X \subseteq U, X$ is rough with respect to knowledge $M$ if and only if $\underline{M} X \neq \bar{M} X$, otherwise $X$ is called definable (or exact) set with respect to $M$.

Also the M-positive, M-negative and M-boundary region of $X$ are defined as

$$
P O S_{M}(X)=\underline{M} X, N E G_{M}(X)=U-\bar{M} X \text { and }
$$
$B N_{M}(X)=\bar{M} X-\underline{M} X$ respectively.

Example 2.2 Let $U=\left\{h_{1}, h_{2}, \cdots, h_{8}\right\}$ be the universe of discourse. There are eight pebbles of different colors. Let $M$ be the knowledge(an equivalence relation) on $U$, so we get a partition of $U$ (categories of $M$ ) as

$U / M=\left\{\left\{h_{1}, h_{5}\right\},\left\{h_{2}, h_{4}, h_{8}\right\},\left\{h_{3}\right\},\left\{h_{6}, h_{7}\right\}\right\}$,

that is $\left\{h_{1}, h_{5}\right\}$ are the pebbles of blue color, $\left\{h_{2}, h_{4}, h_{8}\right\}$ are of red color, $\left\{h_{3}\right\}$ is of green color and $\left\{h_{6}, h_{7}\right\}$ are of yellow color.

Let $X=\left\{h_{4}, h_{6}, h_{7}\right\} \subset U$. The lower and upper approximation of $X$ is

$\underline{M} X=\left\{h_{6}, h_{7}\right\}$

$\bar{M} X=\left\{h_{2}, h_{4}, h_{6}, h_{7}, h_{8}\right\}$

Hence, $\bar{M} X \neq \underline{M} X$. So, the set $X$ is rough with respect to knowledge $M$.
Proposition 2.3 (Pawlak 1991) Suppose that $(U, M)$ is an approximation space and $X, Y \subseteq U$. Then

(1) $\underline{M} X \subseteq X \subseteq \bar{M} X$

(2) $\underline{M} \phi=\bar{M} \phi=\phi, \underline{M} U=\bar{M} U=U$

(3) $\bar{M}(X \cup Y)=\bar{M} X \cup \bar{M} Y$

(4) $\underline{M}(X \cap Y)=\underline{M} X \cap \underline{M} Y$

(5) $X \subseteq Y \Rightarrow \underline{M} X \subseteq \underline{M} Y$

(6) $X \subseteq Y \Rightarrow \bar{M} X \subseteq \bar{M} Y$

(7) $\underline{M}(X \cup Y) \supseteq \underline{M} X \cup \underline{M} Y$

(8) $\bar{M}(X \cap Y) \subseteq \bar{M} X \cap \bar{M} Y$

(9) $\underline{M}(-X)=-\bar{M} X$

(10) $\bar{M}(-X)=-\underline{M} X$

\subsection{Soft set}

The concept of soft set was introduced by Molodtsov (1999). Here we discuss the soft set theory with some properties.

Definition 2.4 Let $U$ be an initial universe, $E$ be the set of parameters related to $U$. Let $P(U)$ denotes the power set of $U, A \subseteq E$ and $F$ be a mapping given by $F: A \rightarrow P(U)$, then the pair $(F, A)$ is called soft set over $\mathrm{U}$. In other words the soft set is characterized by a parameter set and a mapping on parameters. For every $e \in A, F(e)$ is said to be $e$-approximate elements of $U$ and soft set can be viewed as a parameterized family of subsets of $U$.

Maji et al. (2003) introduced equality of two soft sets, subset and super set of a soft set, complement of a soft set, null soft set and absolute soft set with examples.

A soft set $(F, A)$ is called full soft set if $\cup_{e \in A} F(e)=U$.

Definition 2.5 For $A, B \subseteq E$, two soft sets $(F, A)$ and $(G, B)$ over a common universe $U$, we find the set theoretic operations on soft set as:

(1) Soft Subset: The soft set $(F, A)$ is soft subset of $(G, B)$ denoted by $(F, A) \subseteq(G, B)$ if $A \subseteq B$ and $F(x) \subseteq G(x)$ for all $x \in A$. Then $(G, B)$ is said to be a soft super set of $(F, A)$.

(2) Soft Equality: Two soft sets $(F, A)$ and $(G, B)$ over a common universe $U$ are said to be soft equal, denoted by $(F, A)=(G, B)$, if $(F, A)$ is a soft subset of $(G, B)$ and $(G, B)$ is a soft subset of $(F, A)$ that is $(F, A) \subseteq(G, B)$ and $(G, B) \supseteq(F, A)$.

(3) Soft Union: The union of two soft sets $(F, A)$ and $(G, B)$ over the common universe $U$ is the soft set $(H, C)$, where $C=A \cup B$ and for all $e \in C$,

$H(e)=\left\{\begin{array}{l}F(e), \text { if } e \in A-B \\ G(e), \text { if } e \in B-A \\ F(e) \cup G(e), \text { if } e \in A \cap B\end{array}\right.$ 
We denote $(H, C)=(F, A) \cup(G, B)$.

(4) Soft Intersection: The intersection of two soft sets $(F, A)$ and $(G, B)$ over the common universe $U$ is the soft set $(H, C)$, where $C=A \cap B$ and for all $e \in C, H(e)=$ $F(e) \cap G(e)$. We denote $(F, A) \cap(G, B)=(H, C)$.

(5) NOT set of a set of parameters: Let $E=\left\{e_{1}, e_{2}, \cdots, e_{n}\right\}$ be a set of parameters. The NOT set of $E$ is denoted by \rceil $E$ and is defined as $\left.\left.\left.\rceil E=\{\rceil e_{1},\right\rceil e_{2}, \cdots,\right\rceil e_{n}\right\}$, where \rceil $e_{i}=$ not $e_{i}$, for all i, $1 \leq i \leq n$.

(6) Soft Complement: The complement of a soft set $(F, A)$ is denoted by $(F, A)^{c}$ and is defined by $(F, A)^{c}=$ $\left.\left(F^{c},\right\rceil A\right)$, where $\left.F^{c}:\right\rceil A \rightarrow P(U)$ is a mapping given by $\left.F^{c}(e)=U-F(\rceil e\right)$, for all $\left.e \in\right\rceil A$. Clearly, complement of $\left.\left(F^{c},\right\rceil A\right)$ is $(F, A)$, that is $\left((F, A)^{c}\right)^{c}=(F, A)$. But in general the complement of a soft set $(F, A)$ that is, $\left.\left(F^{c},\right\rceil A\right)$ is not a soft set, since $\rceil e_{i} \in E$.

Example 2.6 Let $U=\left\{x_{1}, x_{2}, \cdots, x_{7}\right\}$ be the set of houses under consideration, $E=\left\{a_{1}, a_{2}, a_{3}, a_{4}, a_{5}\right\}$ be set of parameters on $U$ that is $a_{1}$ stands for expensive, $a_{2}$ stands for beautiful, $a_{3}$ stands for wooden, $a_{4}$ stands for cheap and $a_{5}$ stands for green surrounding. Let a mapping $F: E \rightarrow P(U)$ be given an expert views as $F\left(a_{1}\right)=\left\{x_{5}, x_{6}\right\}, F\left(a_{2}\right)=\phi$, $F\left(a_{3}\right)=\left\{x_{4}\right\}, F\left(a_{4}\right)=\left\{x_{3}, x_{7}\right\}, F\left(a_{5}\right)=\left\{x_{1}, x_{6}\right\}$ and $G: E \rightarrow P(U)$ be a mapping (that is another expert giving his views) given by $G\left(a_{1}\right)=\left\{x_{4}, x_{5}, x_{6}\right\}, G\left(a_{2}\right)=\phi$, $G\left(a_{3}\right)=\left\{x_{2}, x_{4}\right\}, G\left(a_{4}\right)=\left\{x_{6}, x_{7}\right\}, G\left(a_{5}\right)=\left\{x_{1}, x_{6}\right\}$.

Let $A=\left\{a_{1}, a_{4}\right\} \subseteq E, B=\left\{a_{1}, a_{4}, a_{5}\right\} \subseteq E$ then the soft set

$$
\begin{aligned}
(F, A) & =\left\{\left(a_{1}, G\left(a_{1}\right)\right),\left(a_{4}, G\left(a_{4}\right)\right)\right\} \\
& =\left\{\left(a_{1},\left\{x_{5}, x_{6}\right\}\right),\left(a_{4},\left\{x_{3}, x_{7}\right\}\right)\right\} \\
(G, B) & =\left\{\left(a_{1}, G\left(a_{1}\right)\right),\left(a_{4}, G\left(a_{4}\right)\right),\left(a_{5}, G\left(a_{5}\right)\right)\right\} \\
& =\left\{\left(a_{1},\left\{x_{4}, x_{5}, x_{6}\right\}\right),\left(a_{4},\left\{x_{3}, x_{7}\right\}\right),\left(a_{5},\left\{x_{1}, x_{6}\right\}\right)\right\}
\end{aligned}
$$

Hence, $(F, A) \subseteq(G, B)$. Since $A \subseteq B$ and $F(a) \subseteq G(a)$, for all $a \in A$.

Soft Complement $\left.(G, B)^{c}=\left(G^{c},\right\rceil B\right)=\{($ not expensive houses, $\left\{x_{1}, x_{2}, x_{3}, x_{7}\right\}$ ), (not cheap houses, $\left\{x_{1}, x_{2}, x_{3}, x_{4}, x_{5}\right\}$ ), (not in the green surrounding, $\left.\left.\left\{x_{2}, x_{3}, x_{4}, x_{5}, x_{7}\right\}\right)\right\}=\left\{(\rceil a_{1}\right.$, $\left.\left.\left\{x_{1}, x_{2}, x_{3}, x_{7}\right\}\right),(\rceil a_{4},\left\{x_{1}, x_{2}, x_{3}, x_{4}, x_{5}\right\}\right),(\rceil a_{5},\left\{x_{2}, x_{3}, x_{4}\right.$, $\left.\left.\left.x_{5}, x_{7}\right\}\right)\right\}$

Example 2.7 Let $U=\left\{x_{1}, x_{2}, \cdots, x_{8}\right\}$ be the initial universe, $E=\left\{a_{1}, a_{2}, \cdots, a_{5}\right\}$ be set of parameters with respect to $U$. Let $F: E \rightarrow P(U)$ be a mapping given by $F\left(a_{1}\right)=\left\{x_{2}, x_{5}, x_{6}, x_{7}\right\}, F\left(a_{2}\right)=\left\{x_{1}, x_{2}, x_{6}\right\}, F\left(a_{3}\right)=$ $\left\{x_{6}, x_{7}\right\}, F\left(a_{4}\right)=\left\{x_{2}, x_{5}, x_{7}\right\}, F\left(a_{5}\right)=\left\{x_{1}, x_{7}\right\}$, and $G: E \rightarrow P(U)$ be a mapping given by $G\left(a_{1}\right)=\left\{x_{2}, x_{8}\right\}$, $G\left(a_{2}\right)=\left\{x_{2}, x_{6}, x_{8}\right\}, G\left(a_{3}\right)=\left\{x_{2}, x_{5}, x_{7}, x_{8}\right\}, G\left(a_{4}\right)=$ $\left\{x_{1}, x_{6}, x_{8}\right\}, G\left(a_{5}\right)=\left\{x_{2}, x_{3}, x_{7}\right\}$.
Let $A=\left\{a_{1}, a_{2}, a_{5}\right\} \subseteq E, B=\left\{a_{2}, a_{4}, a_{5}\right\} \subseteq E$ then the soft set are

$$
\begin{aligned}
& (F, A)=\left\{\left(a_{1}, F\left(a_{1}\right)\right),\left(a_{2}, F\left(a_{2}\right)\right),\left(a_{5}, F\left(a_{5}\right)\right)\right\} \\
= & \left\{\left(a_{1},\left\{x_{2}, x_{5}, x_{6}, x_{7}\right\}\right),\left(a_{2},\left\{x_{1}, x_{2}, x_{6}\right\}\right),\left(a_{5},\left\{x_{1}, x_{7}\right\}\right)\right\} \\
& (G, B)=\left\{\left(a_{2}, G\left(a_{2}\right)\right),\left(a_{4}, G\left(a_{4}\right)\right),\left(a_{5}, G\left(a_{5}\right)\right)\right\} \\
& =\left\{\left(a_{2},\left\{x_{2}, x_{6}, x_{8}\right\}\right),\left(e_{4},\left\{x_{1}, x_{6}, x_{8}\right\}\right),\left(a_{5},\left\{x_{2}, x_{3}, x_{7}\right\}\right)\right\}
\end{aligned}
$$

The union of two soft sets $(F, A)$ and $(G, B)$ is defined as the soft set $(H, C)$, where $C=A \cup B$ and for all $e \in C$, that is

$$
\begin{aligned}
&(F, A) \cup(G, B)=(H, C)=\left(H,\left\{a_{1}, a_{2}, a_{4}, a_{5}\right\}\right) \\
&=\left\{\left(a_{1}, H\left(a_{1}\right)\right),\left(a_{2}, H\left(a_{2}\right)\right),\left(a_{4}, H\left(a_{4}\right)\right),\left(a_{5}, H\left(a_{5}\right)\right)\right\} \\
&=\left\{\left(a_{1},\left\{x_{2}, x_{5}, x_{6}, x_{7}\right\}\right),\left(a_{2},\left\{x_{1}, x_{2}, x_{6}, x_{8}\right\}\right),\left(a_{4},\left\{x_{1}, x_{7}, x_{8}\right\}\right),\right. \\
&\left.\left(a_{5},\left\{x_{1}, x_{2}, x_{3}, x_{7}\right\}\right)\right\}
\end{aligned}
$$

The intersection of two soft sets $(F, A)$ and $(G, B)$ be the soft set $(H, C)$, where $C=A \cap B$ and for all $e \in C$, that is

$$
\begin{aligned}
& (F, A) \cap(G, B)=(H, C)=\left(H,\left\{a_{2}, a_{5}\right\}\right) \\
& \quad=\left\{\left(a_{2}, H\left(a_{2}\right)\right),\left(a_{5}, H\left(a_{5}\right)\right)\right\}=\left\{\left(a_{2},\left\{x_{2}, x_{6}\right\}\right),\left(a_{5},\left\{x_{7}\right\}\right)\right\}
\end{aligned}
$$

Husain and Shivani (2018) had studied some properties on soft set theory with some applications. Also, rough soft setdefinition and properties have been discussed by D. Mohanty (2012).

Feng et al. (2010) provides the definition of soft rough set as for $X \subseteq U$,

$\underline{\operatorname{apr}}_{p}(X)=\{x \in U: \exists a \in A,[u \in F(a) \subseteq X]\}$

$\overline{\operatorname{apr}}_{p}(X)=\{x \in U: \exists a \in A,[u \in F(a), F(a) \cap X \neq \phi]\}$

and $X$ is said to be soft rough set if $\underline{a p r}_{p}(X) \neq \overline{a p r}_{p}(X)$, otherwise $X$ is soft definable.

In this paper it is mentioned that $X \subseteq \overline{a p r}_{p}(X)$ doesn't hold in general.

To eradicate this difficulty, Feng et al. (2011) used full soft set that is $\cup_{e \in A} F(e)=U$ and $\underline{a p r}_{p}(X) \subseteq X \subseteq \overline{a p r}_{p}(X)$ is hold good.

Mohanty et al. (2012) defined soft rough set without using full soft set as for $X \subseteq U$.

${\underset{\operatorname{apr}}{p}}_{p}(X)=\{x \in U: \exists a \in A[x \in F(a) \subseteq X]\}$

$\overline{\operatorname{apr}}_{p}(X)=\left\{\begin{array}{l}M \text { if } X \subseteq M \\ M \cup N \text { if } X \nsubseteq M\end{array}\right.$

Where $M=\cup_{a \in A}\{F(a): F(a) \cap X \neq \phi\}$ and $N=$ $\left.\cap\left\{F^{c}(e): e \in(\rceil A\right)\right\} . X$ is said to be soft rough if $\underline{a p r}_{p}(X) \neq$ $\overline{a p r}_{p}(X)$, otherwise $X$ is soft definable. 
It is nice to note that the property $\underline{\operatorname{apr}}_{p}(X) \subseteq X \subseteq$ $\overline{\operatorname{apr}}_{p}(X)$ holds for $X \subseteq U$ for the definition of soft rough set given by Mohanty et al. (2012) where full soft set not required.

\subsection{Neutrosophic set}

The neutrosophic set theory was introduced by F. Smarandache. It is somehow a generalization of fuzzy set and intuitionistic fuzzy set theory. In this section we present the definition and some operations on neutrosophic set.

Definition 2.8 The neutrosophic set $A$ is a set of objects which is defined on the universe of discourse $U$ as

$A=\left\{\left\langle\frac{x}{\mu_{A}(x), v_{A}(x), \omega_{A}(x)}\right\rangle, x \in U\right\}$,

where the function $\mu, v, \omega: U \rightarrow]^{-} 0,1^{+}\left[\right.$and ${ }^{-} 0 \leq$ $\mu_{A}(x)+v_{A}(x)+\omega_{A}(x) \leq 3^{+}$for all $x \in U$. Here, $\mu_{A}(x), v_{A}(x)$, and $\omega_{A}(\mathrm{x})$ are named as the degree of membership (or Truthness), the degree of indeterminacy, and the degree of non-membership(or Falsehood) of the element $x \in U$ to the set $A$. For two neutrosophic sets $A$ and $B$,

$$
\begin{aligned}
& A=\left\{\left\langle\frac{x}{\mu_{A}(x), v_{A}(x), \omega_{A}(x)}\right\rangle: x \in U\right\}, \text { and } \\
& B=\left\{\left\langle\frac{x}{\mu_{B}(x), v_{B}(x), \omega_{B}(x)}\right\rangle: x \in U\right\},
\end{aligned}
$$

the relations on neutrosophic set are given as follows:

(1) Subset: The neutrosophic set $A$ is a subset of neutrosophic set $B$ if and only if $\mu_{A}(x) \leq \mu_{B}(x), v_{A}(x) \geq$ $v_{B}(x), \omega_{A}(x) \geq \omega_{B}(x)$.

(2) Equality: The neutrosophic set $A$ is equal to neutrosophic set $B$ if and only if $\mu_{A}(x)=\mu_{B}(x), v_{A}(x)=$ $v_{B}(x), \omega_{A}(x)=\omega_{B}(x)$.

(3) Intersection: The intersection of these two neutrosophic sets $A$ and $B$ is given by
(5) Complement: The complement of neutrosophic set $A$ is denoted by $A^{c}$ and defined as

$$
A^{c}=\left\{\left\langle\frac{x}{\omega_{A}(x), 1-v_{A}(x), \mu_{A}(x)}\right\rangle \mid x \in U\right\},
$$

(6) $0_{n}=(0, \alpha, 1)$ and $1_{n}=(1,0,0)$ for $0 \leq \alpha \leq 1$, are called null neutrosophic condition and unit neutrosophic condition respectively.

Example 2.9 Let $U=\left\{x_{1}, x_{2}, x_{3}, x_{4}, x_{5}\right\}$ be a set of quality of features in any television that is, $x_{1}$ is for sharpness, $x_{2}$ is for sound, $x_{3}$ is for color, $x_{4}$ is for internet facilities and $x_{5}$ is for video. Here $A$ is Philips televisions and $B$ is Sony televisions.

$$
\text { Let } \begin{aligned}
A= & \left\{\left\langle\frac{x_{1}}{0.9,0.5,0.4}\right\rangle,\left\langle\frac{x_{2}}{0.7,0.5,0.3}\right\rangle,\left\langle\frac{x_{3}}{0.8,0.2,0.7}\right\rangle,\right. \\
& \left.\left\langle\frac{x_{4}}{0.6,0.7,0.1}\right\rangle,\left\langle\frac{x_{5}}{0.0,0.8,1.0}\right\rangle\right\} \\
= & \left\{\left\langle\frac{x_{1}}{0.9,0.5,0.4}\right\rangle,\left\langle\frac{x_{2}}{0.7,0.5,0.3}\right\rangle,\left\langle\frac{x_{3}}{0.8,0.2,0.7}\right\rangle,\right. \\
& \left.\left\langle\frac{x_{4}}{0.6,0.7,0.1}\right\rangle\right\}
\end{aligned}
$$

Here, for the sharpness $x_{1}$ in Philips televisions, the degree of quality of goodness is 0.9 , the degree of quality of indeterminacy is 0.5 and the degree of worstness is 0.4 and so on. The video quality $x_{5}$ is not considered in Philips televisions, because the degree of membership is 0 and degree of non-membership is 1 .

$$
\begin{aligned}
& \text { Let } B=\left\{\left\langle\frac{x_{1}}{0.9,0.5,0.3}\right\rangle,\left\langle\frac{x_{2}}{0.7,0.5,0.2}\right\rangle,\left\langle\frac{x_{3}}{0.9,0.1,0.5}\right\rangle\right. \\
& \left.\left\langle\frac{x_{4}}{0.7,0.5,0.1}\right\rangle,\left\langle\frac{x_{5}}{0.6,0.4,0.8}\right\rangle\right\}
\end{aligned}
$$

Here, for the sharpness $x_{1}$ in Sony televisions, the degree of quality of goodness is 0.9 , the degree of quality of indeterminacy is 0.5 and the degree of worstness is 0.3 and so on. Hence. $A \subseteq B$.

$$
A \cap B=\left\{\left\langle\frac{x}{\min \left(\mu_{A}(x), \mu_{B}(x)\right), \max \left(v_{A}(x), v_{B}(x)\right), \max \left(\omega_{A}(x), \omega_{B}(x)\right)}\right\rangle \mid x \in U\right\},
$$

(4) Union: The union of these two neutrosophic sets $A$ and $B$ is given by

$$
A \cup B=\left\{\left\langle\frac{x}{\max \left(\mu_{A}(x), \mu_{B}(x)\right), \min \left(v_{A}(x), v_{B}(x)\right), \min \left(\omega_{A}(x), \omega_{B}(x)\right)}\right\rangle \mid x \in U\right\},
$$


Example 2.10 Let $U=\left\{x_{1}, x_{2}, x_{3}, x_{4}, x_{5}\right\}$ be different treatments that is, $x_{1}$ stands for physical therapy, $x_{2}$ stands for radiology, $x_{3}$ stands for immunotherapy, $x_{4}$ stands for phototherapy and $x_{5}$ stands for chemotherapy. Here $A$ is Delhi city and $B$ is Mumbai.

$$
\begin{gathered}
\text { Let } A=\left\{\left\langle\frac{x_{1}}{0.7,0.2,0.5}\right\rangle,\left\langle\frac{x_{2}}{0.8,0.4,0.3}\right\rangle,\left\langle\frac{x_{3}}{0.5,0.5,0.5}\right\rangle,\right. \\
\left.\left\langle\frac{x_{4}}{0.5,0.7,0.2}\right\rangle,\left\langle\frac{x_{5}}{0.8,0.5,0.3}\right\rangle\right\} \\
\text { and } B=\left\{\left\langle\frac{x_{1}}{0.9,0.2,0.5}\right\rangle,\left\langle\frac{x_{2}}{0.7,0.4,0.3}\right\rangle,\left\langle\frac{x_{3}}{0.8,0.7,0.1}\right\rangle,\right. \\
\left.\left\langle\frac{x_{4}}{0.5,0.7,0.6}\right\rangle,\left\langle\frac{x_{5}}{0.6,0.4,0.2}\right\rangle\right\}
\end{gathered}
$$

be neutrosophic sets. Then union, intersection and compliment of two neutrosophic sets $A$ and $B$ is

$$
\begin{gathered}
A \cup B=\left\{\left\langle\frac{x_{1}}{0.9,0.2,0.5}\right\rangle,\left\langle\frac{x_{2}}{0.8,0.4,0.3}\right\rangle,\left\langle\frac{x_{3}}{0.8,0.5,0.1}\right\rangle,\right. \\
\left.\left\langle\frac{x_{4}}{0.5,0.7,0.2}\right\rangle,\left\langle\frac{x_{5}}{0.8,0.4,0.2}\right\rangle\right\} \\
A \cap B=\left\{\left\langle\frac{x_{1}}{0.7,0.2,0.5}\right\rangle,\left\langle\frac{x_{2}}{0.7,0.4,0.3}\right\rangle,\left\langle\frac{x_{3}}{0.5,0.7,0.5}\right\rangle\right. \\
\left.\left\langle\frac{x_{4}}{0.5,0.7,0.6}\right\rangle,\left\langle\frac{x_{5}}{0.6,0.5,0.3}\right\rangle\right\}
\end{gathered}
$$

For the city Delhi and Mumbai, we get the degree of quality of goodness in physical therapy is atleast 0.7 , degree of indeterminacy is atmost 0.2 and degree of quality of worstness is atmost 0.5 .

$$
\begin{gathered}
A^{c}=\left\{\left\langle\frac{x_{1}}{0.5,0.8,0.7}\right\rangle,\left\langle\frac{x_{2}}{0.3,0.6,0.8}\right\rangle,\left\langle\frac{x_{3}}{0.5,0.5,0.5}\right\rangle,\right. \\
\left.\left\langle\frac{x_{4}}{0.2,0.3,0.5}\right\rangle,\left\langle\frac{x_{5}}{0.3,0.5,0.8}\right\rangle\right\}
\end{gathered}
$$

\subsection{Neutrosophic soft set}

Maji introduced the concept of neutrosophic soft set in 2013. Further, more scholarly approaches in respect of neutrosophic soft set are developed by Bhutani and Aggarwal (2017), Mohanty and Kalia (2015).

Definition 2.11 (Maji 2013) Let $U$ be an initial universe set and $E$ be the set of parameters on $U, A \subseteq E$. Let NS(U) be the set of all neutrosophic sets of $U$, then the collection $\left(F_{N}, A\right)$ is called neutrosophic soft set over $U$, where $F_{N}$ is a mapping given by $F_{N}: A \rightarrow N S(U)$.

Example 2.12 Let $U$ be the set of dresses for young girls under consideration and $E$ be the set of parameters. Let $U=\left\{x_{1}, x_{2}, x_{3}, x_{4}, x_{5}\right\}$ and $A=\left\{a_{1}, a_{2}, a_{3}\right\} \subseteq E$, where $E=\left\{a_{1}, a_{2}, a_{3}, a_{4}, a_{5}\right\}$ that is $E=\{$ beautiful, shinning, costly, modern, regular\}. Suppose that

$$
\begin{gathered}
F_{N}\left(a_{1}\right)=\left\{\left\langle\frac{x_{1}}{0.6,0.5,0.4}\right\rangle,\left\langle\frac{x_{2}}{0.4,0.7,0.3}\right\rangle,\left\langle\frac{x_{3}}{0.8,0.5,0.4}\right\rangle,\right. \\
\left.\left\langle\frac{x_{4}}{0.9,0.6,0.2}\right\rangle,\left\langle\frac{x_{5}}{0.0,0.7,1.0}\right\rangle\right\} \\
F_{N}\left(a_{2}\right)=\left\{\left\langle\frac{x_{1}}{0.9,0.6,0.3}\right\rangle,\left\langle\frac{x_{2}}{0.7,0.4,0.2}\right\rangle,\left\langle\frac{x_{3}}{0.6,0.2,0.3}\right\rangle,\right. \\
\left.\left\langle\frac{x_{4}}{0.7,0.3,0.2}\right\rangle,\left\langle\frac{x_{5}}{0.8,0.2,0.3}\right\rangle\right\} \\
F_{N}\left(a_{3}\right)=\left\{\left\langle\frac{x_{1}}{0.7,0.4,0.6}\right\rangle,\left\langle\frac{x_{2}}{0.9,0.3,0.5}\right\rangle,\left\langle\frac{x_{3}}{0.7,0.8,0.5}\right\rangle,\right. \\
\left.\left\langle\frac{x_{4}}{0.0,0.5,1.0}\right\rangle,\left\langle\frac{x_{5}}{0.6,0.1,0.8}\right\rangle\right\}
\end{gathered}
$$

Here, $F_{N}\left(a_{1}\right)$ means dresses(beautiful) whose functional value is the neutrosophic set $\left\langle\frac{x_{1}}{0.6,0.5,0.4}\right\rangle$,

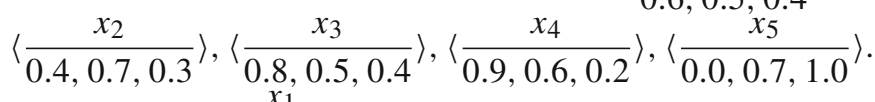
An element $\left\langle\frac{x_{1}}{0.9,0.6,0.3}\right\rangle$ be $a_{2}-$ approximate element of $F_{N}$ whose degree of shinning of $x_{1}$ is 0.9 , degree of indeterminacy in shinning of $x_{1}$ is 0.6 and degree of dullness (that is, degree of non-membership or falsehood of shinning) of $x_{1}$ is 0.3 .

Consider the neutrosophic soft set $\left(F_{N}, A\right)$, where $F_{N}$ : $A \rightarrow N S(U)$ describes the beautiful dresses, shinning dresses and costly dresses.

$$
\begin{aligned}
N & S_{A}(U)=\left(F_{N}, A\right)=\left\{\left(a_{1}, F_{N}\left(a_{1}\right)\right),\left(a_{2}, F_{N}\left(a_{2}\right)\right),\left(a_{3}, F_{N}\left(a_{3}\right)\right)\right\} \\
= & \left\{\left(a_{1},\left\{\left\langle\frac{x_{1}}{0.6,0.5,0.4}\right\rangle,\left\langle\frac{x_{2}}{0.4,0.7,0.3}\right\rangle,\right.\right.\right. \\
& \left.\left.\left\langle\frac{x_{3}}{0.8,0.5,0.4}\right\rangle,\left\langle\frac{x_{4}}{0.9,0.6,0.2}\right\rangle\right\}\right), \\
& \left(a_{2},\left\{\left\langle\frac{x_{1}}{0.9,0.6,0.3}\right\rangle,\left\langle\frac{x_{2}}{0.7,0.4,0.2}\right\rangle,\left\langle\frac{x_{3}}{0.6,0.2,0.3}\right\rangle,\right.\right. \\
& \left.\left.\left\langle\frac{x_{4}}{0.7,0.3,0.2}\right\rangle,\left\langle\frac{x_{5}}{0.8,0.2,0.3}\right\rangle\right\}\right), \\
& \left(a_{3},\left\{\left\langle\frac{x_{1}}{0.7,0.4,0.6}\right\rangle,\left\langle\frac{x_{2}}{0.9,0.3,0.5}\right\rangle,\left\langle\frac{x_{3}}{0.7,0.8,0.5}\right.\right.\right. \\
& \rangle,\left\langle\frac{x_{5}}{0.6,0.1,0.8}\right\rangle\right\}\right)\right\}
\end{aligned}
$$

For example Miss Shela wants to buy shinning dresses to attend a marriage party then the neutrosophic soft set, for $B=\left\{a_{2}\right\}$ is

$$
\begin{aligned}
& N S_{B}(U)=\left(F_{N}, B\right)=\left\{\left(a_{2}, F_{N}\left(a_{2}\right)\right)\right\} \\
& =\left\langle a_{2},\left\{\left\langle\frac{x_{1}}{0.9,0.6,0.3}\right\rangle,\left\langle\frac{x_{2}}{0.7,0.4,0.2}\right\rangle,\left\langle\frac{x_{3}}{0.6,0.2,0.3}\right\rangle,\right.\right. \\
& \left.\left.\quad\left\langle\frac{x_{4}}{0.7,0.3,0.2}\right\rangle,\left\langle\frac{x_{5}}{0.8,0.2,0.3}\right\rangle\right\}\right)
\end{aligned}
$$

So Miss Shela will choose the dress $x_{1}$ as it has highest degree of truthness. 
Now we define neutrosophic soft subset, equal, union and intersection on $U$.

Definition 2.13 Let $\left(F_{N}, A\right)$ and $\left(G_{N}, B\right)$ be two neutrosophic soft sets over the common universe $U .\left(F_{N}, A\right)$ is said to be neutrosophic soft subset of $\left(G_{N}, B\right)$ if $A \subset B$, and $T_{F_{N}(a)}(x) \leq T_{G_{N}(a)}(x), I_{F_{N}(a)}(x) \geq I_{G_{N}(a)}(x), F_{F_{N}(a)}(x) \geq$ $F_{G_{N}(a)}(x), \forall a \in A, x \in U$. We denote it by $\left(F_{N}, A\right) \subseteq$ $\left(G_{N}, B\right)$. At that time we say $\left(G_{N}, B\right)$ be the neutrosophic soft super set of $\left(F_{N}, A\right)$.

Definition 2.14 Two neutrosophic soft sets $\left(F_{N}, A\right)$ and $\left(G_{N}, B\right)$ over the common universe $U$ are said to be equal if $\left(F_{N}, A\right)$ is neutrosophic soft subset of $\left(G_{N}, B\right)$ and $\left(G_{N}, B\right)$ is neutrosophic soft subset of $\left(F_{N}, A\right)$. We denote it by $\left(F_{N}, A\right)=\left(G_{N}, B\right)$.

Definition 2.15 Let $\left(H_{N}, A\right)$ and $\left(G_{N}, B\right)$ be two neutrosophic soft sets over the common universe $U$. Then the union of $\left(H_{N}, A\right)$ and $\left(G_{N}, B\right)$ is denoted by $\left(H_{N}, A\right) \cup\left(G_{N}, B\right)$ and is defined by $\left(H_{N}, A\right) \cup\left(G_{N}, B\right)=\left(K_{N}, C\right)$, where $C=$ $A \cup B$ and for $m \in U$ the truth-membership, indeterminacymembership and falsity-membership of $\left(K_{N}, C\right)$ are follows, respectively

$$
\begin{aligned}
& T_{K_{N}(a)}(m)=\left\{\begin{array}{l}
T_{H_{N}(a)}(m), \text { if } a \in A-B \\
T_{G_{N}(a)}(m), \text { if } a \in B-A \\
\max \left(T_{H_{N}(a)}(m), T_{G_{N}(a)}(m)\right), \text { if } a \in A \cap B
\end{array}\right. \\
& I_{K_{N}(a)}(m)=\left\{\begin{array}{l}
I_{H_{N}(a)}(m), \text { if } a \in A-B \\
I_{G_{N}(a)}(m), \text { if } a \in B-A \\
\frac{I_{H_{N}(a)}(m)+I_{G_{N}(a)}(m)}{2}, \text { if } a \in A \cap B
\end{array}\right. \\
& F_{K_{N}(a)}(m)=\left\{\begin{array}{l}
F_{H_{N}(a)}(m), \text { if } a \in A-B \\
F_{G_{N}(a)}(m), \text { if } a \in B-A \\
\min \left(F_{H_{N}(a)}(m), F_{G_{N}(a)}(m)\right), \quad \text { if } a \in A \cap B
\end{array}\right.
\end{aligned}
$$

Definition 2.16 Let $\left(H_{N}, A\right)$ and $\left(G_{N}, B\right)$ be two neutrosophic soft sets over the common universe $U$. Then the intersection of $\left(H_{N}, A\right)$ and $\left(G_{N}, B\right)$ is denoted by $\left(H_{N}, A\right) \cap\left(G_{N}, B\right)$ and is defined by $\left(H_{N}, A\right) \cap\left(G_{N}, B\right)=$ $\left(K_{N}, C\right)$, where $C=A \cap B$ and for $m \in U$ the truth-membership, indeterminacy-membership and falsitymembership of $\left(K_{N}, C\right)$ are follows, respectively

$$
\begin{aligned}
T_{K_{N}(a)}(m) & =\min \left(T_{H_{N}(a)}(m), T_{G_{N}(a)}(m)\right), \\
I_{K_{N}(a)}(m) & =\max \left(I_{H_{N}(a)}(m), I_{G_{N}(a)}(m)\right) \\
F_{K_{N}(a)}(m) & =\max \left(F_{H_{N}(a)}(m), F_{G_{N}(a)}(m)\right), \forall a \in C .
\end{aligned}
$$

\section{Neutrosophic soft set with roughness}

In this section, $N S_{A}$-lower and $N S_{A}$-upper approximations are introduced and their properties are deduced and illustrated with examples. We can find the notation $S_{A}(X)$, for $X \subseteq U$ and $E$ is a set of parameters, $A \subseteq E$,

$S_{A}(X)=\{u \in U: \exists e \in A[u \in F(e) \subseteq X]\}$.

Clearly, $S_{A}(X) \subseteq X, S_{A}(\phi)=\phi$ and $S_{A}(U) \subseteq U$.

We note that, neutrosophic soft rough set is defined here without using full soft set. We can also find neutrosophic soft rough set which was defined in some manner by Broumi et al. (2014),Al-Quran et al. (2019) and Dhar (2020) using full soft set. But these are totally different from the definition given below

Definition 3.1 Let $U$ be a nonempty universe. Let $E$ be set of parameters, $A \subseteq E$ and NS(U) be the set of all neutrosophic sets of $U$. The collection $S=\left(F_{N}, A\right)$ be the neutrosophic soft set over $U$, where $F_{N}$ be a mapping given by $F_{N}: A \rightarrow$ $N S(U)$. Then $P=\left(U, F_{N}, A\right)$ is called neutrosophic soft approximation space. Now for $X \subseteq U$, we define $N S_{A}$-lower and $N S_{A}$-upper approximation as

$$
\begin{aligned}
& \operatorname{apr}_{N S_{A}}(X)=\left\{\left(e,\left\{\left\langle\frac{u}{\mu_{A}(u), v_{A}(u), \omega_{A}(u)}\right\rangle\right\}\right)\right. \\
& \left.\in N S_{A}(U): u \in S_{A}(X)\right\} \\
& \text { and } \overline{\operatorname{apr}}_{N S_{A}}(X)=N S_{A}(U)-\underline{a p r}_{N S_{A}}\left(X^{c}\right) \text {, }
\end{aligned}
$$

where $S_{A}(X)=\{u \in U: \exists e \in A[u \in F(e) \subset X]\}$.

If $\underline{\operatorname{apr}}_{N S_{A}}(X) \neq \overline{a p r}_{N S_{A}}(X)$, then $X$ is neutrosophic soft rough set, otherwise $X$ is called neutrosophic soft definable set.

Example 3.2 Let $U=\left\{x_{1}, x_{2}, \cdots, x_{10}\right\}$ be ten private new buildings are be sold and $E=\left\{f_{1}, f_{2}, f_{3}, f_{4}, f_{5}\right\}$ be a set of parameters such that $f_{1}$ be the parameter that the building looks like police quarter, the parameter $f_{2}$ be the buildings looks like peon quarters, $f_{3}$ be the doctor's quarter, $f_{4}$ be officer's quarter and $f_{5}$ be teacher's quarter. Let $F: E \rightarrow P(U)$ be a mapping given by $F\left(f_{1}\right)=\left\{x_{1}, x_{4}, x_{5}\right\}, F\left(f_{2}\right)=\phi$, $F\left(f_{3}\right)=\left\{x_{4}, x_{5}\right\}, F\left(f_{4}\right)=\left\{x_{1}, x_{2}, x_{3}\right\}, F\left(f_{5}\right)=\left\{x_{3}, x_{6}\right\}$, and $F\left(f_{6}\right)=\left\{x_{3}, x_{4}, x_{7}\right\}$.

Now we define a mapping $F_{N}: E \rightarrow N S(U)$ by

$$
\begin{aligned}
F_{N} & \left(f_{1}\right)=F_{N} \text { (building looks like police quarter) } \\
= & \left\{\left\langle\frac{x_{1}}{0.7,0.5,0.3}\right\rangle,\left\langle\frac{x_{2}}{0.0,0.5,1.0}\right\rangle,\left\langle\frac{x_{3}}{0.0,0.9,1.0}\right\rangle,\right. \\
& \left\langle\frac{x_{4}}{0.8,0.3,0.5}\right\rangle,\left\langle\frac{x_{5}}{0.9,0.7,0.2}\right\rangle,\left\langle\frac{x_{6}}{0.0,0.8,1.0}\right\rangle, \\
& \left\langle\frac{x_{7}}{0.0,0.2,1.0}\right\rangle,\left\langle\frac{x_{8}}{0.0,0.7,1.0}\right\rangle,\left\langle\frac{x_{9}}{0.0,0.6,1.0}\right\rangle
\end{aligned}
$$




$$
\begin{aligned}
& \left.\left\langle\frac{x_{10}}{0.0,0.5,1.0}\right\rangle\right\} \\
= & \left\{\left\langle\frac{x_{1}}{0.7,0.5,0.3}\right\rangle,\left\langle\frac{x_{4}}{0.8,0.3,0.5}\right\rangle,\left\langle\frac{x_{5}}{0.9,0.7,0.2}\right\rangle\right\}
\end{aligned}
$$

Here, building $x_{2}, x_{3}, x_{6}, x_{7}, x_{8}, x_{9}$ and $x_{10}$ are not considered because the degree of membership is 0 and degree of non-membership is 1 .

$$
\begin{aligned}
& F_{N}\left(f_{2}\right)=F_{N}(\text { building looks like peon quarter })=\phi \\
& F_{N}\left(f_{3}\right)=F_{N} \text { (building looks like doctor's quarter) } \\
&=\left\{\left\langle\frac{x_{4}}{0.9,0.5,0.6}\right\rangle,\left\langle\frac{x_{5}}{0.8,0.6,0.3}\right\rangle\right\} \\
& F_{N}\left(f_{4}\right)=F_{N} \text { (building looks like officer's quarter) } \\
&=\left\{\left\langle\frac{x_{1}}{0.8,0.3,0.2}\right\rangle,\left\langle\frac{x_{2}}{0.9,0.4,0.7}\right\rangle,\right. \\
&\left.\left\langle\frac{x_{3}}{0.6,0.7,0.3}\right\rangle\right\} \\
& F_{N}\left(f_{5}\right)=F_{N}(\text { building looks like teacher's quarter) } \\
&=\left\{\left\langle\frac{x_{3}}{0.7,0.4,0.1}\right\rangle,\left\langle\frac{x_{6}}{0.5,0.3,0.6}\right\rangle\right\}
\end{aligned}
$$

Now neutrosophic soft set over $U$ is

$$
\begin{aligned}
&\left(F_{N}, E\right)=\left\{\left(f_{1}, F_{N}\left(f_{1}\right)\right),\left(f_{2}, F_{N}\left(f_{2}\right)\right),\left(f_{3}, F_{N}\left(f_{3}\right)\right),\right. \\
&\left.\quad\left(f_{4}, F_{N}\left(f_{4}\right)\right),\left(f_{5}, F_{N}\left(f_{5}\right)\right)\right\} \\
&=\left\{\left(f_{1},\left\{\left\langle\frac{x_{1},}{0.7,0.5,0.3}\right\rangle,\left\langle\frac{x_{4}}{0.8,0.3,0.5}\right\rangle,\right.\right.\right. \\
&\left.\left.\left\langle\frac{x_{5}}{0.9,0.7,0.2}\right\rangle\right\}\right),\left(f_{2}, \phi\right),\left(f_{3},\left\{\left\langle\frac{x_{4}}{0.9,0.5,0.6}\right\rangle,\right.\right. \\
&\left.\left.\left\langle\frac{x_{5}}{0.8,0.6,0.3}\right\rangle\right\}\right),\left(f_{4},\left\{\left\langle\frac{x_{1}}{0.8,0.3,0.2}\right\rangle,\right.\right. \\
&\left.\left.\left\langle\frac{x_{2}}{0.9,0.4,0.7}\right\rangle,\left\langle\frac{x_{3}}{0.6,0.7,0.3}\right\rangle\right\}\right), \\
&\left.\left(f_{5},\left\{\left\langle\frac{x_{3}}{0.7,0.4,0.1}\right\rangle,\left\langle\frac{x_{6}}{0.5,0.3,0.6}\right\rangle\right\}\right)\right\}=N S(U)
\end{aligned}
$$

Let $X=\left\{x_{4}, x_{5}, x_{8}\right\}, X^{c}=\left\{x_{1}, x_{2}, x_{3}, x_{6}, x_{7}, x_{9}, x_{10}\right\} \subset$ $U$ and $A=\left\{f_{1}, f_{3}, f_{5}\right\} \subset E$. Here, $S_{A}(X)=\left\{x_{4}, x_{5}\right\} \subset$ $X \subset U$. Then the neutrosophic soft $\operatorname{set}\left(F_{N}, A\right)$ is

$$
\begin{aligned}
& \left(F_{N}, A\right)=\left\{\left(f_{1}, F_{N}\left(f_{1}\right)\right),\left(f_{3}, F_{N}\left(f_{3}\right)\right),\left(f_{5}, F_{N}\left(f_{5}\right)\right)\right\} \\
& =\left\{\left(f_{1},\left\{\left\langle\frac{x_{1},}{0.7,0.5,0.3}\right\rangle,\left\langle\frac{x_{4}}{0.8,0.3,0.5}\right\rangle,\right.\right.\right. \\
& \left.\left.\left\langle\frac{x_{5}}{0.9,0.7,0.2}\right\rangle\right\}\right),\left(f_{3},\left\{\left\langle\frac{x_{4}}{0.9,0.5,0.6}\right\rangle,\right.\right. \\
& \left.\left.\left\langle\frac{x_{5}}{0.8,0.6,0.3}\right\rangle\right\}\right),\left(f_{5},\left\{\left\langle\frac{x_{3}}{0.7,0.4,0.1}\right\rangle,\right.\right. \\
& \left.\left.\left\langle\frac{x_{6}}{0.5,0.3,0.6}\right\rangle\right)\right\}=N S_{A}(U)
\end{aligned}
$$

Now, $N S_{A}$-lower approximation of $X$ is

$$
\underline{a p r}_{N S_{A}}(X)=\left\{\left(f_{3},\left\{\left\langle\frac{x_{4}}{0.9,0.5,0.6}\right\rangle,\left\langle\frac{x_{5}}{0.8,0.6,0.3}\right\rangle\right\}\right)\right\}
$$

$$
\underline{a p r}_{N S_{A}}\left(X^{c}\right)=\left\{\left(f_{5},\left\{\left\langle\frac{x_{3}}{0.7,0.4,0.1}\right\rangle,\left\langle\frac{x_{6}}{0.5,0.3,0.6}\right\rangle\right\}\right)\right\}
$$

The $N S_{A}$-upper approximation of $X$ is

$$
\begin{aligned}
& \overline{a p r}_{N S_{A}}(X)=\left\{\left(f_{1},\left\{\left\langle\frac{x_{1},}{0.7,0.5,0.3}\right\rangle,\left\langle\frac{x_{4}}{0.8,0.3,0.5}\right\rangle,\right.\right.\right. \\
& \left.\left.\left\langle\frac{x_{5}}{0.9,0.7,0.2}\right\rangle\right\}\right),\left(f_{3},\left\{\left\langle\frac{x_{4}}{0.9,0.5,0.6}\right\rangle,\right.\right. \\
& \left.\left.\left.\left\langle\frac{x_{5}}{0.8,0.6,0.3}\right\rangle\right\}\right)\right\}
\end{aligned}
$$

Thus, $X$ is rough with respect to knowledge $N S_{A}$, since $\underline{a p r}_{N S_{A}}(X) \neq \overline{a p r}_{N S_{A}}(X)$.

Theorem 3.3 Let $S=\left(F_{N}, A\right)$ be neutrosophic soft set over $U, P=\left(U, F_{N}, A\right)$ be a neutrosophic soft approximation space and $X, Y \subseteq U$, then we have

1. $\operatorname{apr}_{N S_{A}}(X) \subseteq S_{A}(X) \subseteq \overline{a p r}_{N S_{A}}(X)$,

2. $\operatorname{apr}_{N S_{A}}(\phi)=\phi, \overline{a p r}_{N S_{A}}(\phi)=\phi$,

3. $\operatorname{apr}_{N S_{A}}(U)=N S_{A}(U)=\overline{a p r}_{N S_{A}}(U)$,

4. $X \subseteq Y \Rightarrow \underline{a p r}_{N S_{A}}(X) \subseteq \underline{a p r}_{N S_{A}}(Y)$,

5. $X \subseteq Y \Rightarrow \overline{\overline{a p r}}_{N S_{A}}(X) \subseteq \overline{\overline{a p r}}_{N S_{A}}(Y)$,

6. $\underline{a p r}_{N S_{A}}(X \cap Y) \subseteq \underline{a p r}_{N S_{A}}(X) \cap \underline{a p r}_{N S_{A}}(Y)$,

7. $\underline{a p r}_{N S_{A}}(X \cup Y) \supseteq \underline{a p r}_{N S_{A}}(X) \cup \underline{a p r}_{N S_{A}}(Y)$,

8. $\overline{\overline{a p r}}_{N S_{A}}(X \cap Y) \subseteq \overline{\overline{a p r}}_{N S_{A}}(X) \cap \overline{\overline{a p r}}_{N S_{A}}(Y)$.

Proof From definition of $N S_{A}$-lower and $N S_{A}$ upper approximation, (1),(2) and (3) are straightforward. So we prove the remaining.

Assume that $X \subseteq Y$.

Let $u \in \underline{a p r}_{N S_{A}}(X)$, by definition there exists one $a \in A$ such that $u \in F(a) \subseteq X$ and $\left(a,\left\{\left\langle\frac{u}{\mu_{A}(u), v_{A}(u), \omega_{A}(u)}\right\rangle\right\}\right) \in$ $N S_{A}(U)$.

So that $u \in F(a) \subseteq X \subseteq Y$ and $\left(a,\left\{\left\langle\frac{u}{\mu_{A}(u), v_{A}(u), \omega_{A}(u)}\right\rangle\right\}\right) \in$ $N S_{A}(U)$.

This implies $u \in \underline{a p r}_{N S_{A}}(Y)$.

Hence, $\underline{a p r}_{N S_{A}}(X) \subseteq \underline{a p r}_{N S_{A}}(Y)$. This proves (4).

Remaining properties come directly.

Definition 3.4 Let $S=\left(F_{N}, A\right)$ be a neutrosophic soft set over $U$. For any $e_{1}, e_{2} \in A$, there exists $e_{3} \in A$ such that $F\left(e_{3}\right)=F\left(e_{1}\right) \cap F\left(e_{2}\right) \neq \phi$ and $\left(e_{1},\left\{\left\langle\frac{u}{\mu_{A}(u), v_{A}(u), \omega_{A}(u)}\right\rangle\right\}\right) \in$ $N S_{A}(U), \quad\left(e_{2},\left\{\left\langle\frac{u}{\mu_{A}(u), v_{A}(u), \omega_{A}(u)}\right\rangle\right\}\right) \in N S_{A}(U)$, $\mu_{A}(u), v_{A}(u), \omega_{A}(u) \in[0,1]$ for $u \in U$, then $S$ is called intersection complete neutrosophic soft set.

Proposition 3.5 Let $S=\left(F_{N}, A\right)$ be an intersection complete neutrosophic soft set over $U$ and $P=\left(U, F_{N}, A\right)$ be 
a neutrosophic soft approximation space. Then we have

$\underline{\operatorname{apr}}_{N S_{A}}(X \cap Y)=\underline{\operatorname{apr}}_{N S_{A}}(X) \cap \underline{\operatorname{apr}}_{N S_{A}}(Y)$.

Proof We have only to show $\underline{a p r}_{N S_{A}}(X \cap Y) \supseteq \underline{\operatorname{apr}}_{N S_{A}}(X) \cap$ $\underline{\operatorname{apr}}_{N S_{A}}(Y)$, since,

$\underline{\operatorname{apr}}_{N S_{A}}(X \cap Y) \subseteq \underline{\operatorname{apr}}_{N S_{A}}(X) \cap \underline{\operatorname{apr}}_{N S_{A}}(Y)$

(which is proved in theorem 3.3).

Let $u \in \underline{\operatorname{apr}}_{N S_{A}}(X) \cap \underline{\operatorname{apr}}_{N S_{A}}(Y)$, then there exists $e_{1}, e_{2} \in$ A such that $u \in F\left(e_{1}\right) \subseteq X,\left(e_{1},\left\{\left\langle\frac{u}{\mu_{A}(u), v_{A}(u), \omega_{A}(u)}\right\rangle\right\}\right) \in$ $N S_{A}(U)$, and $u \in F\left(e_{2}\right) \subseteq Y\left(e_{2},\left\{\left\langle\frac{u}{\mu_{A}(u), v_{A}(u), \omega_{A}(u)}\right\rangle\right\}\right) \in$ $N S_{A}(U)$. By definition of intersection complete soft set, there exists $e_{3} \in A$ such that $u \in F\left(e_{3}\right)=F\left(e_{1}\right) \cap F\left(e_{2}\right) \subseteq$ $X \cap Y$.

Hence, $u \in \underline{a p r}_{N S_{A}}(X \cap Y)$. Therefore,

$\underline{\operatorname{apr}}_{N S_{A}}(X) \cap \underline{\operatorname{apr}}_{N S_{A}}(Y) \subseteq \underline{a p r}_{N S_{A}}(X \cap Y)$

Example 3.6 Let $U=\left\{h_{1}, h_{2}, \cdots, h_{10}\right\}$ be universe of discourse and $E=\left\{e_{1}, e_{2}, \cdots, e_{7}\right\}$ be a set of parameters. Let $F: E \rightarrow P(U)$ be a mapping given by $F\left(e_{1}\right)=\left\{h_{1}, h_{5}\right\}$, $F\left(e_{2}\right)=\phi, F\left(e_{3}\right)=\left\{h_{3}\right\}, F\left(e_{4}\right)=\left\{h_{1}, h_{10}\right\}, F\left(e_{5}\right)=$ $\left\{h_{5}\right\}, F\left(e_{6}\right)=\left\{h_{6}\right\}$ and $F\left(e_{7}\right)=\left\{h_{9}, h_{10}\right\}$.

Let $X=\left\{h_{1}, h_{3}, h_{5}, h_{7}, h_{8}, h_{9}\right\}, Y=\left\{h_{1}, h_{2}, h_{3}, h_{10}\right\}$, then $X^{c}=\left\{h_{2}, h_{4}, h_{6}, h_{10}\right\}, Y^{c}=\left\{h_{4}, h_{5}, h_{6}, h_{7}, h_{8}, h_{9}\right\} \subseteq$ $U$ and let $A=\left\{e_{1}, e_{3}, e_{4}, e_{5}, e_{6}\right\} \subseteq E$.

Thus, $S_{A}(X)=\left\{h_{1}, h_{3}, h_{5}\right\} \subset X$ and $S_{A}(Y)=\left\{h_{1}, h_{3}, h_{5}\right.$, $\left.h_{10}\right\} \subset Y$. Then neutrosophic soft set over $U$ be

$$
\begin{aligned}
& \left(F_{N}, E\right)=\left\{\left(e_{1},\left\{\left\langle\frac{h_{1}}{0.2,0.4,0.5}\right\rangle,\left\langle\frac{h_{5}}{0.9,0.7,0.1}\right\rangle\right),\right.\right. \\
& \left(e_{2}, \phi\right),\left(e_{3},\left\{\left\langle\frac{h_{3}}{0.9,0.2,0.4}\right\rangle\right),\right. \\
& \left(e_{4},\left\{\left\langle\frac{h_{1}}{0.7,0.2,0.1}\right\rangle,\left\langle\frac{h_{10}}{1.0,0.1,0.5}\right\rangle\right\}\right), \\
& \left(e_{5},\left\{\left\langle\frac{h_{5}}{0.8,0.5,0.5}\right\rangle\right\}\right), \\
& \left(e_{6},\left\{\left\langle\frac{h_{6}}{0.7,0.1,0.3}\right\rangle\right\}\right),\left(e_{7},\left\{\left\langle\frac{h_{9}}{0.9,0.1,0.0}\right\rangle,\right.\right. \\
& \left.\left.\left.\left\langle\frac{h_{10}}{1.0,0.3,0.5}\right\rangle\right\}\right)\right\} \\
& \left(F_{N}, A\right)=\left\{\left(e_{1},\left\{\left\langle\frac{h_{1}}{0.2,0.4,0.5}\right\rangle,\left\langle\frac{h_{5}}{0.9,0.7,0.1}\right\rangle\right\}\right),\right. \\
& \left(e_{3},\left\{\left\langle\frac{h_{3}}{0.9,0.2,0.4}\right\rangle\right\}\right), \\
& \left(e_{4},\left\{\left\langle\frac{h_{1}}{0.7,0.2,0.1}\right\rangle,\left\langle\frac{h_{10}}{1.0,0.1,0.5}\right\rangle\right\}\right),
\end{aligned}
$$

$$
\begin{aligned}
& \left(e_{5},\left\{\left\langle\frac{h_{5}}{0.8,0.5,0.5}\right\rangle\right\}\right), \\
& \left.\left(e_{6},\left\{\left\langle\frac{h_{6}}{0.7,0.1,0.3}\right\rangle\right\}\right)\right\} \\
& \frac{a p r}{N S_{A}}(X)=\left\{\left(e_{1},\left\{\left\langle\frac{h_{1}}{0.2,0.4,0.5}\right\rangle,\left\langle\frac{h_{5}}{0.9,0.7,0.1}\right\rangle\right\}\right),\right. \\
& \left.\left(e_{3},\left\{\left\langle\frac{h_{3}}{0.9,0.2,0.4}\right\rangle\right\}\right)\right\} \\
& \frac{a p r}{N S_{A}}(Y)=\left\{\left(e_{1},\left\{\left\langle\frac{h_{1}}{0.2,0.4,0.5}\right\rangle,\left\langle\frac{h_{5}}{0.9,0.7,0.1}\right\rangle\right\}\right),\right. \\
& \left(e_{3},\left\{\left\langle\frac{h_{3}}{0.9,0.2,0.4}\right\rangle\right\}\right), \\
& \left.\left(e_{4},\left\{\left\langle\frac{h_{1}}{0.7,0.2,0.1}\right\rangle,\left\langle\frac{h_{10}}{1.0,0.1,0.5}\right\rangle\right\}\right)\right\}
\end{aligned}
$$

Now, $X \cap Y=\left\{h_{1}, h_{3}\right\},(X \cap Y)^{c}=\left\{h_{2}, h_{4}, h_{5}, h_{6}, h_{7}, h_{8}\right.$, $\left.h_{9}, h_{10}\right\}$.

$$
\begin{aligned}
& {\frac{\operatorname{apr}}{N S_{A}}}(X \cap Y)=\left\{\left(e_{3},\left\{\left\langle\frac{h_{3}}{0.9,0.2,0.4}\right\rangle\right\}\right)\right\} \\
& \text { Hence, }{\frac{\operatorname{apr}}{N S_{A}}}(X \cap Y) \subseteq \frac{\operatorname{apr}}{N S_{A}}(X) \cap \underline{\operatorname{apr}} N S_{A}(Y) \\
& =\left\{\left(e_{1},\left\{\left\langle\frac{h_{1}}{0.2,0.4,0.5}\right\rangle,\left\langle\frac{h_{5}}{0.9,0.7,0.1}\right\rangle\right\}\right)\right. \\
& \left.\left(e_{3},\left\{\left\langle\frac{h_{3}}{0.9,0.2,0.4}\right\rangle\right\}\right)\right\}
\end{aligned}
$$

Next, $X \cup Y=\left\{h_{1}, h_{2}, h_{3}, h_{5}, h_{7}, h_{8}, h_{9}, h_{10}\right\}$ and

$$
\begin{aligned}
& \underline{\operatorname{apr}}_{N S_{A}}(X \cup Y)=\left\{\left(e_{1},\left\{\left\langle\frac{h_{1}}{0.2,0.4,0.5}\right\rangle,\left\langle\frac{h_{5}}{0.9,0.7,0.1}\right\rangle\right\}\right),\right. \\
& \left(e_{3},\left\{\left\langle\frac{h_{3}}{0.9,0.2,0.4}\right\rangle\right\}\right) \\
& \left(e_{4},\left\{\left\langle\frac{h_{1}}{0.7,0.2,0.1}\right\rangle,\left\langle\frac{h_{10}}{1.0,0.1,0.5}\right\rangle\right\}\right), \\
& \left.\left(e_{5},\left\{\left\langle\frac{h_{5}}{0.8,0.5,0.5}\right\rangle\right\}\right)\right\}
\end{aligned}
$$

Therefore, $\underline{\operatorname{apr}}_{N S_{A}}(X) \cup \underline{\operatorname{apr}}_{N S_{A}}(Y) \subseteq \underline{\operatorname{apr}}_{N S_{A}}(X \cup Y)$.

Now, $\underline{\operatorname{apr}}_{N S_{A}}\left((X \cap Y)^{c}\right)=\left\{\left(e_{5},\left\{\left\langle\frac{h_{5}}{0.8,0.5,0.5}\right\rangle\right\}\right)\right.$,

$$
\begin{aligned}
& \left.\left(e_{6},\left\{\left\langle\frac{h_{6}}{0.7,0.1,0.3}\right\rangle\right\}\right)\right\} \\
& \overline{a p r}_{N S_{A}}(X \cap Y)=\left\{\left(e_{1},\left\{\left\langle\frac{h_{1}}{0.2,0.4,0.5}\right\rangle,\left\langle\frac{h_{5}}{0.9,0.7,0.1}\right\rangle\right\}\right),\right. \\
& \left(e_{3},\left\{\left\langle\frac{h_{3}}{0.9,0.2,0.4}\right\rangle\right\}\right), \\
& \left.\left(e_{4},\left\{\left\langle\frac{h_{1}}{0.7,0.2,0.1}\right\rangle,\left\langle\frac{h_{10}}{1.0,0.1,0.5}\right\rangle\right\}\right)\right\} \\
& \underline{a p r}_{N S_{A}}\left(X^{c}\right)=\left\{\left(e_{6},\left\{\left\langle\frac{h_{6}}{0.7,0.1,0.3}\right\rangle\right\}\right)\right\}=\underline{a p r}_{N S_{A}}\left(Y^{c}\right) .
\end{aligned}
$$

So that 


$$
\begin{aligned}
& \overline{a p r}_{N S_{A}}(X)=\overline{a p r}_{N S_{A}}(Y)=\left\{\left(e_{1},\left\{\left\langle\frac{h_{1}}{0.2,0.4,0.5}\right\rangle,\right.\right.\right. \\
& \left.\left.\left\langle\frac{h_{5}}{0.9,0.7,0.1}\right\rangle\right\}\right), \\
& \left(e_{3},\left\{\left\langle\frac{h_{3}}{0.9,0.2,0.4}\right\rangle\right),\right. \\
& \left(e_{4},\left\{\left\langle\frac{h_{1}}{0.7,0.2,0.1}\right\rangle,\left\langle\frac{h_{10}}{1.0,0.1,0.5}\right\rangle\right\}\right), \\
& \left.\left(e_{5},\left\{\left\langle\frac{h_{5}}{0.8,0.5,0.5}\right\rangle\right\}\right)\right\}
\end{aligned}
$$

Therefore, $\overline{a p r}_{N S_{A}}(X \cap Y) \subseteq \overline{a p r}_{N S_{A}}(X) \cap \overline{a p r}_{N S_{A}}(Y)$.

\subsection{Equality on neutrosophic soft rough set}

In this section, we defined equality on neutrosophic soft rough set.

Definition 3.7 Let $\left(F_{N}, A\right)$ be an neutrosophic soft set on a universe $U, A \subseteq E$. For all $X, Y \subseteq U$, we define binary relation

1. Sets $X$ and $Y$ are bottom $N S_{A}$ equal $\left(X \preccurlyeq N S_{A} Y\right)$ if and only if $\frac{a p r}{N S_{A}}(X)=\underline{a p r}{ }_{N S_{A}}(Y)$

2. Sets $X$ and $Y$ are top $N S_{A}$ equal $\left(X \prec_{N S_{A}} Y\right)$ if and only if $\overline{a p r}_{N S_{A}}(X)=\overline{a p r}_{N S_{A}}(Y)$

3. Sets $X$ and $Y$ are $N S_{A}$ equal $\left(X \approx_{N S_{A}} Y\right)$ if and only if $\underline{a p r}_{N S_{A}}(X)=\underline{a p r}_{N S_{A}}(Y)$ and $\overline{a p r}_{N S_{A}}(X)=$ $\overline{\operatorname{apr}}_{N S_{A}} \overline{(Y)}$

Proposition 3.8 Let $\left(F_{N}, A\right)$ be neutrosophic soft set over universe $U, A \subseteq E$. Then

1. If $X \subseteq Y$ and $Y \prec_{N S_{A}} \phi$, then $X \prec_{N S_{A}} \phi$,

2. If $X \subseteq Y$ and $X \prec_{N S_{A}} U$, then $Y \prec_{N S_{A}} U$,

3. If $X \subseteq Y$ and $Y \preccurlyeq_{N S_{A}} \phi$, then $X \preccurlyeq_{N S_{A}} \phi$,

4. If $X \subseteq Y$ and $Y \preccurlyeq_{N S_{A}} U$, then $X \preccurlyeq_{N S_{A}} U$.

Proof (1) Given $X \subseteq Y$ and $Y \prec_{N S_{A}} \phi$, so that $\overline{a p r}_{N S_{A}}(X) \subseteq$ $\overline{a p r}_{N S_{A}}(Y)$ and $\overline{a p r}_{N S_{A}}(Y)=\phi$.

Hence, $\quad \overline{a p r}_{N S_{A}}(X)=\phi=\overline{a p r}_{N S_{A}}(\phi)$

(2) Given, $X \prec_{N S_{A}} U$ and $X \subseteq Y$, then $\overline{a p r}_{N S_{A}}(X)=$ $\overline{a p r}_{N S_{A}}(U)$ and $\overline{a p r}_{N S_{A}}(X) \subseteq \overline{a p r}_{N S_{A}}(Y)$. But we know that

$$
\begin{gathered}
\overline{a p r}_{N S_{A}}(Y) \subseteq \overline{a p r}_{N S_{A}}(U), \text { hence } \\
\overline{a p r}_{N S_{A}}(Y)=\overline{a p r}_{N S_{A}}(U)
\end{gathered}
$$

Remaining properties comes directly.

We note here that $X \prec_{N S_{A}} Y$ if and only if $X \cap Y \prec_{N S_{A}} X$ and $X \cap Y \prec_{N S_{A}} Y$ is not true in general.

\section{Dispensable}

In this section, we shall discuss about dispensable and indispensable of neutrosophic soft set. Let $\left(L_{N}, A\right),\left(M_{N}, B\right)$ and $\left(P_{N}, C\right)$ be neutrosophic soft set on $U$, where $A, B, C \subseteq$ $S$ and $L_{N}: A \rightarrow N S(U), M_{N}: B \rightarrow N S(U)$, $P_{N}: C \rightarrow N S(U)$ be the mappings. Let $\left(F_{N}, S\right)=$ $\left\{\left(L_{N}, A\right),\left(M_{N}, B\right),\left(P_{N}, C\right)\right\}$. We define approximate neutrosophic soft set, which is denoted by APP.

$$
\begin{aligned}
& A P P\left(\left(F_{N}, S\right)\right)=A P P\left\{\left(L_{N}, A\right),\left(M_{N}, B\right),\left(P_{N}, C\right)\right\} \\
& \quad=\left\{\left(l_{\alpha}, m_{\beta}, p_{\delta}\right), \cap\left\{L_{N}\left(l_{\alpha}\right), M_{N}\left(m_{\beta}\right),\right.\right. \\
& \left.\left.\quad P_{N}\left(n_{\delta}\right)\right\} \mid 1 \leq \alpha, \beta, \delta \leq n\right\} \\
& \quad=\left\{\left(e_{i}, F_{N}\left(e_{i}\right)\right) \mid e_{i} \in S\right\},
\end{aligned}
$$

where $l_{\alpha} \in A, m_{\beta} \in B, p_{\delta} \in C$ and $e_{i} \in S \subseteq A \times B \times C$, $F_{N}\left(e_{i}\right)=\cap\left\{L_{N}\left(l_{\alpha}\right), M_{N}\left(m_{\beta}\right), P_{N}\left(n_{\delta}\right)\right\}$.

Also we write the difference in approximate neutrosophic soft set as $A P P\left(\left(F_{N}, S\right)-\left(L_{N}, A\right)\right)=A P P\left(\left(M_{N}, B\right)\right.$, $\left.\left(P_{N}, C\right)\right)$

Definition 4.1 Two approximate Neutrosophic soft sets APP $\left(I_{N}, X\right)$ and $\operatorname{APP}\left(J_{N}, Y\right)$ are said to be equal that is $\operatorname{APP}\left(I_{N}, X\right)=\mathrm{APP}$

$\left(J_{N}, Y\right)$ if for every $x_{i} \in X$ there exists one $y_{j} \in Y$ such that $I_{N}\left(x_{i}\right)=J_{N}\left(y_{j}\right)$ for some $1 \leq i, j \leq n$ and for every $y_{j} \in Y$ there exists one $x_{i} \in X$ such that $J_{N}\left(y_{j}\right)=I_{N}\left(x_{i}\right)$ for some $1 \leq i, j \leq n$, where $X, Y \subseteq E$ and $I_{N}: X \rightarrow$ $N S(U), J_{N}: Y \rightarrow N S(U)$.

Definition 4.2 The neutrosophic soft set $\left(L_{N}, A\right)$ is dispensable in $\left\{\left(L_{N}, A\right),\left(M_{N}, B\right),\left(P_{N}, C\right)\right\}$ if $A P P\left(\left(F_{N}, S\right)\right)=$ $A P P\left(\left(F_{N}, S\right)-\left(L_{N}, A\right)\right)$. And if $\operatorname{APP}\left(\left(F_{N}, S\right)\right) \neq$ APP $\left(\left(F_{N}, S\right)-\left(L_{N}, A\right)\right)$, then $\left(L_{N}, A\right)$ is indispensable in $\left(F_{N}, S\right)$.

Definition 4.3 The neutrosophic soft set $\left(F_{N}, S\right)$ is independent if each $\left(L_{N}, A\right) \subseteq\left(F_{N}, S\right)$ is indispensable in $\left(F_{N}, S\right)$. Otherwise neutrosophic soft set $\left(F_{N}, S\right)$ is dependent.

Example 4.4 Let $U=\left\{x_{1}, x_{2}, \cdots, x_{6}\right\}$ be six most affected states in India due to Corona virus infection. Here $x_{1}$ is a group of persons from the state Maharashtra is detected corona positive, $x_{2}$ is a group of persons from the state Kerala is detected corona positive, $x_{3}$ is from Tamil Nadu, $x_{4}$ is from Delhi, $x_{5}$ is from Uttar Pradesh and $x_{6}$ is from Karnnataka. Let $E=\left\{e_{1}, e_{2}, \cdots, e_{11}\right\}$ be the set of parameters with respect to corona virus infection symptoms in the human body such that $e_{1}$ is aches, $e_{2}$ is difficult in breathing, $e_{3}$ is tiredness, $e_{4}$ is chill. $e_{5}$ is fever and cough, $e_{6}$ is sore throat, $e_{7}$ is loss of smell, $e_{8}$ is loss of taste, $e_{9}$ is headache, $e_{10}$ is diaarhea and $e_{11}$ is severe vomiting. Let $A=\left\{e_{1}, e_{2}, e_{5}\right\}$, $B=\left\{e_{6}, e_{7}, e_{8}\right\}, C=\left\{e_{9}, e_{10}, e_{11}\right\} \subseteq E$. 
Assume that $L_{N}\left(e_{1}\right)=\left\{x_{3}, x_{5}, x_{6}\right\}$ that is, aches symptoms are marked in human body due to corona infection in states Tamil Nadu, Uttar Pradesh and Karnataka, $L_{N}\left(e_{2}\right)=$ $\left\{x_{2}, x_{4}\right\}$ that is, difficulty breathing is marked in human body due to corona infection in states Kerala and Delhi and $L_{N}\left(e_{5}\right)=\left\{x_{1}, x_{3}, x_{4}\right\}$ that is, fever and cough is marked in human body due to corona infection in states Maharashtra, Tamil Nadu and Delhi. $M_{N}\left(e_{6}\right)=\left\{x_{1}, x_{5}, x_{6}\right\}$, $M_{N}\left(e_{7}\right)=\left\{x_{2}, x_{3}, x_{4}\right\}$ and $M_{N}\left(e_{8}\right)=\left\{x_{2}, x_{6}\right\}$. Similary, $P_{N}\left(e_{9}\right)=\left\{x_{2}, x_{5}, x_{6}\right\}, P_{N}\left(e_{10}\right)=\left\{x_{1}, x_{5}\right\}$ and $P_{N}\left(e_{11}\right)=$ $\left\{x_{3}, x_{4}\right\}$.

$$
\begin{aligned}
& \text { Now, }\left(L_{N}, A\right)=\left\{\left(e_{1}, L_{N}\left(e_{1}\right)\right),\left(e_{2}, L_{N}\left(e_{2}\right)\right),\right. \\
& \left.\left(e_{5}, L_{N}\left(e_{5}\right)\right)\right\} \\
& =\left\{\left(e_{1},\left\{\left\langle\frac{x_{3}}{1.0,0.9,0.8}\right\rangle,\left\langle\frac{x_{5}}{0.7,0.6,0.9}\right\rangle,\right.\right.\right. \\
& \left.\left.\left\langle\frac{x_{6}}{0.8,0.3,0.7}\right\rangle\right\}\right),\left(e_{2},\left\{\left\langle\frac{x_{2}}{0.7,0.6,0.9}\right\rangle,\right.\right. \\
& \left.\left.\left\langle\frac{x_{4}}{0.8,0.6,0.9}\right\rangle\right\}\right),\left(e_{5},\left\{\left\langle\frac{x_{1}}{0.6,0.3,0.2}\right\rangle,\right.\right. \\
& \left.\left.\left.\left\langle\frac{x_{3}}{0.7,0.8,0.6}\right\rangle,\left\langle\frac{x_{4}}{0.3,0.5,0.8}\right\rangle\right\}\right)\right\} \\
& \left(M_{N}, B\right)=\left\{\left(e_{6}, M_{N}\left(e_{6}\right)\right),\left(e_{7}, M_{N}\left(e_{7}\right)\right),\right. \\
& \left.\left(e_{8}, M_{N}\left(e_{8}\right)\right)\right\} \\
& =\left\{\left(e_{6},\left\{\left\langle\frac{x_{1}}{0.7,0.4,0.1}\right\rangle,\left\langle\frac{x_{5}}{0.8,0.5,0.7}\right\rangle,\right.\right.\right. \\
& \left.\left.\left\langle\frac{x_{6}}{0.8,0.3,0.7}\right\rangle\right\}\right),\left(e_{7},\left\{\left\langle\frac{x_{1}}{0.7,0.4,0.1}\right\rangle,\right.\right. \\
& \left.\left.\left\langle\frac{x_{3}}{0.9,0.4,0.6}\right\rangle,\left\langle\frac{x_{4}}{0.6,0.4,0.3}\right\rangle\right\}\right),\left(e_{8},\left\{\left\langle\frac{x_{2}}{0.9,0.4,0.6}\right\rangle,\right.\right. \\
& \left.\left.\left.\left\langle\frac{x_{6}}{1.0,0.5,0.3}\right\rangle\right\}\right)\right\} \\
& \left(P_{N}, C\right)=\left\{\left(e_{9}, P_{N}\left(e_{9}\right)\right),\left(e_{10}, P_{N}\left(e_{10}\right)\right),\right. \\
& \left.\left(e_{11}, P_{N}\left(e_{11}\right)\right)\right\} \\
& =\left\{\left(e_{9},\left\{\left\langle\frac{x_{2}}{1.0,0.6,0.4}\right\rangle,\left\langle\frac{x_{5}}{0.9,0.2,0.7}\right\rangle,\right.\right.\right. \\
& \left.\left.\left\langle\frac{x_{6}}{0.7,0.4,0.3}\right\rangle\right\}\right),\left(e_{10},\left\{\left\langle\frac{x_{1}}{0.9,0.3,0.1}\right\rangle,\right.\right. \\
& \left.\left.\left\langle\frac{x_{5}}{0.7,0.4,0.1}\right\rangle\right\}\right),\left(e_{11},\left\{\left\langle\frac{x_{3}}{0.8,0.4,0.3}\right\rangle,\right.\right. \\
& \left.\left.\left.\left\langle\frac{x_{4}}{0.7,0.2,0.1}\right\rangle\right\}\right)\right\}
\end{aligned}
$$

Now let us consider approximate neutrosophic soft set AP $P\left(\left(F_{N}, S\right)\right)$ which describe the common symptoms of corona that generally find in people when they were affected.

$$
\begin{array}{rl}
A & P P\left(\left(L_{N}, A\right),\left(M_{N}, B\right),\left(P_{N}, C\right)\right) \\
& =A P P\left(\left(F_{N}, S\right)\right)(\text { say }) \\
& =\left\{\left(\left(e_{1}, e_{6}, e_{9}\right),\left\{\left\langle\frac{x_{5}}{0.7,0.6,0.9}\right\rangle,\left\langle\frac{x_{6}}{0.8,0.4,0.7}\right\rangle\right\}\right),\right.
\end{array}
$$

$$
\begin{aligned}
& \left(\left(e_{1}, e_{6}, e_{10}\right),\right. \\
& \left.\left\{\left\langle\frac{x_{5}}{0.7,0.6,0.9}\right\rangle\right\}\right),\left(\left(e_{1}, e_{7}, e_{11}\right),\left\{\left\langle\frac{x_{3}}{0.8,0.9,0.8}\right\rangle\right\}\right), \\
& \left(\left(e_{1}, e_{8}, e_{9}\right),\left\{\left\langle\frac{x_{6}}{0.7,0.5,0.7}\right\rangle\right\}\right), \\
& \left(\left(e_{2}, e_{7}, e_{11}\right),\left\{\left\langle\frac{x_{4}}{0.6,0.6,0.9}\right\rangle\right\}\right), \\
& \left(\left(e_{5}, e_{6}, e_{10}\right),\left\{\left\langle\frac{x_{1}}{0.6,0.4,0.2}\right\rangle\right\}\right),\left(\left(e_{5}, e_{7}, e_{11}\right)\right. \\
& \left.\left.\left\{\left\langle\frac{x_{3}}{0.7,0.8,0.6}\right\rangle,\left\langle\frac{x_{4}}{0.3,0.5,0.8}\right\rangle\right\}\right)\right\} \\
& =\left\{\left(s_{1}, F_{N}\left(s_{1}\right)\right),\left(s_{2}, F_{N}\left(s_{2}\right)\right),\left(s_{3}, F_{N}\left(s_{3}\right)\right)\right. \\
& \left(s_{4}, F_{N}\left(s_{4}\right)\right), \\
& \left.\left(s_{5}, F_{N}\left(s_{5}\right)\right),\left(s_{6}, F_{N}\left(s_{6}\right)\right),\left(s_{7}, F_{N}\left(s_{7}\right)\right)\right\}
\end{aligned}
$$

where $s_{1}=\left(e_{1}, e_{6}, e_{9}\right)$ be a parameter with respect to symptoms of aches and sore throat and headache, in human body $F_{N}\left(s_{1}\right)=\left\{\left\langle\frac{x_{5}}{0.8,0.5,0.6}\right\rangle,\left\langle\frac{x_{6}}{0.6,0.4,0.3}\right\rangle\right\}$. Similarly, $s_{2}=\left\{e_{1}, e_{6}, e_{10}\right\}, s_{3}=\left\{e_{1}, e_{7}, e_{11}\right\}, s_{4}=$ $\left\{e_{1}, e_{8}, e_{9}\right\}, s_{5}=\left\{e_{2}, e_{7}, e_{11}\right\}, s_{6}=\left\{e_{5}, e_{6}, e_{10}\right\}$ and $s_{7}=$ $\left\{e_{5}, e_{7}, e_{11}\right\}$. As $L_{N}\left(e_{1}\right) \cap M_{N}\left(e_{6}\right) \cap P_{N}\left(e_{11}\right)=\phi$ the element $\left(\left(e_{1}, e_{6}, e_{11}\right), \phi\right)$ in $A P P\left(F_{N}, S\right)$ is not written.

$$
\begin{array}{rl}
\text { Now, } A P P\left(\left(F_{N}, S\right)-\left(L_{N}, A\right)\right)=A P P\left(\left(M_{N}, B\right),\left(P_{N}, C\right)\right) \\
=A P P\left(Z_{N}, T\right), \text { suppose } \\
=\left\{\left(\left(e_{6}, e_{9}\right),\left\{\left\langle\frac{x_{5}}{0.8,0.5,0.7}\right\rangle,\left\langle\frac{x_{6}}{0.7,0.4,0.7}\right\rangle\right\}\right),\left(\left(e_{6}, e_{10}\right),\right.\right. \\
\left.\left\{\left\langle\frac{x_{1}}{0.7,0.4,0.1}\right\rangle,\left\langle\frac{x_{5}}{0.7,0.5,0.7}\right\rangle\right\}\right), \\
& \left(\left(e_{7}, e_{10}\right),\left\{\left\langle\frac{x_{1}}{0.7,0.4,0.1}\right\rangle\right\}\right), \\
& \left(\left(e_{7}, e_{11}\right),\left\{\left\langle\frac{x_{3}}{0.8,0.4,0.6}\right\rangle,\left\langle\frac{x_{4}}{0.6,0.4,0.3}\right\rangle\right\}\right),\left(\left(e_{8}, e_{9}\right),\right. \\
& \left.\left\{\left\langle\frac{x_{2}}{0.9,0.6,0.6}\right\rangle,\left\langle\frac{x_{6}}{0.7,0.5,0.3}\right\}\right)\right\} \\
= & \left\{\left(t_{1}, Z_{N}\left(t_{1}\right)\right),\left(t_{2}, Z_{N}\left(t_{2}\right)\right),\left(t_{3}, Z_{N}\left(t_{3}\right)\right),\left(t_{4}, Z_{N}\left(t_{4}\right)\right),\right. \\
& \left.\left(t_{5}, Z_{N}\left(t_{5}\right)\right)\right\} \\
\neq A & P P\left(\left(F_{N}, S\right)\right)
\end{array}
$$

Since, though $F_{N}\left(s_{1}\right)=\left\{\left\langle\frac{x_{5}}{0.7,0.6,0.9}\right\rangle\left\langle\frac{x_{6}}{0.8,0.4,0.7}\right\rangle\right\}=$ $Z_{N}\left(t_{1}\right)$, but $F_{N}\left(s_{2}\right)=\left\{\left\langle\frac{x_{5}}{0.7,0.6,0.9}\right\rangle\right\} \neq Z_{N}\left(t_{i}\right), 1 \leq$ $i \leq 5, F_{N}\left(s_{3}\right)=\left\{\left\langle\frac{x_{3}}{0.8,0.9,0.8}\right\rangle\right\} \neq Z_{N}\left(t_{i}\right), F_{N}\left(s_{4}\right)=$ $\left\{\left\langle\frac{x_{6}}{0.7,0.5,0.7}\right\rangle\right\} \neq Z_{N}\left(t_{i}\right), F_{N}\left(s_{5}\right)=\left\{\left\langle\frac{x_{4}}{0.6,0.4,0.9}\right\rangle\right\} \neq$ $Z_{N}\left(t_{i}\right), F_{N}\left(s_{6}\right)=\left\{\left\langle\frac{x_{1}}{0.6,0.4,0.2}\right\rangle\right\} \neq Z_{N}\left(t_{i}\right), Z_{N}\left(t_{2}\right)=$ $\left\{\left\langle\frac{x_{1}}{0.7,0.4,0.1}\right\rangle,\left\langle\frac{x_{5}}{0.7,0.5,0.7}\right\rangle\right\} \neq F_{N}\left(s_{j}\right)$ and $Z\left(t_{5}\right)=$ $\left\{\left\langle\frac{x_{2}}{0.9,0.6,0.6}\right\rangle,\left\langle\frac{x_{6}}{0.7,0.5,0.3}\right\rangle\right\} \neq F_{N}\left(s_{j}\right)$, where $1 \leq j \leq$ 7. 
Hence, $\left(L_{N}, A\right)$ is indispensable in $\left(F_{N}, S\right)$.

$$
\begin{aligned}
& \text { Now, } A P P\left(\left(F_{N}, S\right)-\left(M_{N}, B\right)\right)=A P P\left(\left(L_{N}, A\right),\right. \\
&\left.\quad\left(P_{N}, C\right)\right)=A P P\left(Q_{N}, R\right), \text { say } \\
&=\left\{\left(\left(e_{1}, e_{9}\right),\left\{\left\langle\frac{x_{5}}{0.7,0.6,0.9}\right\rangle,\left\langle\frac{x_{6}}{0.7,0.6,0.9}\right\rangle\right\}\right),\left(\left(e_{1}, e_{10}\right),\right.\right. \\
&\left\{\left\langle\frac{x_{5}}{0.7,0.6,0.9}\right\rangle\right),\left(\left(e_{1}, e_{11}\right),\left\{\left\langle\frac{x_{3}}{0.8,0.9,0.8}\right\rangle\right\}\right),\left(\left(e_{2}, e_{9}\right),\right. \\
&\left.\left\{\left\langle\frac{x_{2}}{0.7,0.6,0.9}\right\rangle\right\}\right),\left(\left(e_{2}, e_{11}\right),\left\{\left\langle\frac{x_{4}}{0.7,0.6,0.9}\right\rangle\right),\left(\left(e_{5}, e_{10}\right),\right.\right. \\
&\left\{\left\langle\frac{x_{1}}{0.6,0.3,0.2}\right\rangle\right),\left(\left(e_{5}, e_{11}\right),\left\{\left\langle\frac{x_{3}}{0.7,0.8,0.6}\right\rangle,\left\langle\frac{x_{4}}{0.3,0.5,0.8}\right\rangle\right)\right\} \\
&=\left\{\left(r_{1}, Q_{N}\left(r_{1}\right)\right),\left(r_{2}, Q_{N}\left(r_{2}\right)\right),\left(r_{3}, Q_{N}\left(r_{3}\right)\right),\left(r_{4}, Q_{N}\left(r_{4}\right)\right),\right. \\
&\left.\left(r_{5}, Q_{N}\left(r_{5}\right)\right)\right\} \\
& \neq A P P\left(\left(F_{N}, S\right)\right)
\end{aligned}
$$

Hence, $\left(M_{N}, B\right)$ is indispensable in $\left(F_{N}, S\right)$.

$$
\begin{array}{rl}
A & P P\left(\left(F_{N}, S\right)-\left(P_{N}, C\right)\right)=A P P\left(\left(L_{N}, A\right),\right. \\
& \left.\left(M_{N}, B\right)\right)=A P P\left(V_{N}, D\right) \\
& \left\{\left(\left(e_{1}, e_{6}\right),\left\{\left\langle\frac{x_{5}}{0.7,0.6,0.9}\right\rangle,\left\langle\frac{x_{6}}{0.6,0.3,0.7}\right\rangle\right\}\right),\right. \\
& \left(\left(e_{1}, e_{7}\right),\left\{\left\langle\frac{x_{3}}{0.9,0.9,0.8}\right\rangle\right),\right. \\
& \left(\left(e_{1}, e_{8}\right),\left\{\left\langle\frac{x_{6}}{0.8,0.5,0.7}\right\rangle\right\}\right), \\
& \left(\left(e_{2}, e_{7}\right),\left\{\left\langle\frac{x_{4}}{0.6,0.6,0.9}\right\}\right),\left(\left(e_{2}, e_{8}\right),\right.\right. \\
\left\{\left\langle\frac{x_{2}}{0.7,0.6,0.9}\right\rangle\right),\left(\left(e_{5}, e_{6}\right),\left\{\left\langle\frac{x_{1}}{0.6,0.4,0.2}\right\rangle\right),\right. \\
\left(\left(e_{5}, e_{7}\right),\left\{\left\langle\frac{x_{1}}{0.6,0.4,0.2}\right\rangle,\right.\right. \\
\left.\left.\left\langle\frac{x_{3}}{0.7,0.8,0.6}\right\rangle,\left\langle\frac{x_{4}}{0.3,0.5,0.8}\right\rangle\right)\right\} \\
=\left\{\left(d_{1}, V_{N}\left(d_{1}\right)\right),\left(d_{2}, V_{N}\left(d_{2}\right)\right),\left(d_{3}, V_{N}\left(d_{3}\right)\right),\right. \\
\left.\left(d_{4}, V_{N}\left(d_{4}\right)\right),\left(d_{5}, V_{N}\left(d_{5}\right)\right)\right\} \\
\neq A P P\left(\left(F_{N}, S\right)\right)
\end{array}
$$

Hence, $\left(P_{N}, C\right)$ is indispensable in $\left(F_{N}, S\right)$. Therefore, $\left(F_{N}, S\right)$ is independent.

\section{Conclusion}

To conclude this paper explicitly, the notion of neutrosophic soft rough set has been defined in new manner by combining of three theories that is rough set theory, soft set theory and neutrosophic set theory. The study of their basic properties like union, intersection and complement are discussed with examples. Some authors have defined soft rough set using full soft set which is not more convenient to handle indeterminant and incomplete data as it require all the information which is not always practically possible. However, in this article neu- trosophic soft rough set is established without using full soft set and also equality and dispensability on neutrosophic soft rough set are illustrated with examples, to deal with indeterminant and incomplete data in a more convenient to real life problems.

Funding The authors (authors including corresponding author) declare that they have no funding for this study.

\section{Declarations}

Conflict of interest The authors declare that they have no conflict of interest.

Ethical Approval This article does not contain any studies with human participants or animals performed by any of the authors. $\square$ The authors declare that they have no known competing financial interests or personal relationships that could have appeared to influence the work reported in this paper. $\square$ This is one original research work.

\section{References}

Al-Quran A, Hassan N, Marei E (2019) A novel approach to neutrosophic soft rough set under uncertainty. Symmetry 11:384

Bhutani K, Aggarwal S (2017) Neutrosophic rough soft set—a decision making approach to appendicitis problem. Neutrosophic sets and systems 16

Broumi S, Smarandache F, Dhar M (2014) Rough neutrosophic sets. Ital J Pure Appl Math 32:493-502

Das M, Mohanty D (2021) Dispensability on soft rough set theory. Int J Eng Sci Math 10(4):1-10

Dhar M (2020) Neutrosophic soft block matrices and some of its properties. Int J Neutrosophic Sci 12(1):39-49

Feng F, Li C, Dawaz B, Ali MI (2010) Soft sets combined with fuzzy sets and rough sets: a tentative approach. Soft Comput 14:899-911

Feng F, Liu X, Leoreanu-Fotea V, Jun YB (2011) Soft sets and soft rough sets. Inf Sci 18:1125-1137

Husain S, Shivani K (2018) A study of properties of soft set and applications. Int Res J Eng Technol 5:363-372

Lin TY (1988) Neighborhood systems and relational database. In: Proceedings of 1988 ACM Sixteen Annual Computer Science Conference, February 23-25

Maji PK, Biswas R, Roy AR (2003) Soft set theory. Comput Math Appl 45:555-562

Maji PK (2013) Neutosophic soft set. Annals Fuzzy Math Inf 5:157-168

Mohanty D, Kalia N, Pattanayak L, Nayak BB (2012) An introduction to rough soft set. Math Sci Int Res J 1(3):927-936

Mohanty D, Kalia N (2015) A note on rough neutrosophic soft set. Proceedings of the National Conference on Recent Trends in Mathematics and Information Technology ISBN: 978-82208-77-8

Molodtsov D (1999) Soft set theory first results. Comput Math Appl $37: 19-31$

Pawlak Z (1982) Rough set theory. Int J Comput Inf Sci 11:341-356

Pawlak Z (1991) Rough sets-theoretical aspects of reasoning about data. Kluwer, Dor drecht

Shabir M, Ali MI, Shaheen T (2013) Another approach to soft rough sets. Knowledge- Based Syst 40:72-80

Smarandache F (1999) A unifying field in logic, neutrosophy: neutrosophic probability, set and logic. American Research Press, Santa $\mathrm{Fe}$ 
Smarandache F (2018) Extension of soft set to hypersoft set, and then to plithogenic hypersoft set. Neutrosophic Sets Syst 22:168-170

Zakowski W (1983) Approximations in the space $(U, \pi)$. Demonstr Math XVI:761-769
Zhang C, Li D, Kang X, Song D, Sangaiah AK, Broumi S (2020) Neutrosophic fusion of rough set theory: an overview. Comput Ind $115: 103117$

Publisher's Note Springer Nature remains neutral with regard to jurisdictional claims in published maps and institutional affiliations. 